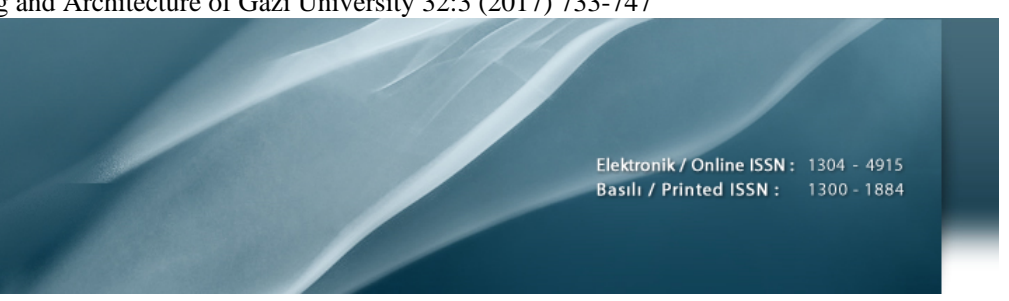

\title{
İzmir ve çevresinin 3-B kabuk hız yapısı
}

\author{
Çağlar Özer ${ }^{1,2}$ (D),Orhan Polat ${ }^{2}$ (D)*
}

${ }^{1}$ Dokuz Eylül Üniversitesi, Fen Bilimleri Enstitüsü, Jeofizik Mühendisliği Anabilim Dalı, Buca, 35160, İzmir, Türkiye

${ }^{2}$ Dokuz Eylül Üniversitesi, Mühendislik Fakültesi, Jeofizik Mühendisliği Bölümü, Sismoloji Anabilim Dalı, Buca, 35160, İzmir, Türkiye

\section{Ö N E Ç I K A N L A R}

- İzmir, Batı Anadolu'da sismik hız yapısını belirlemeye yönelik ilk çalışma

- İzmir jeotermal potansiyelinin ortaya konmasi

- Yerel deprem tomografisi yönteminin jeotermal alanlara uygulanması

Makale Bilgileri

Geliș: 30.03.2016

Kabul: 27.02.2017

DOI:

10.17341/gazimmfd.337620

Anahtar Kelimeler:

\section{3-B yerel deprem}

tomografisi,

ege bölgesi,

izmir,

kabuk hız yapısı

\section{ÖZET}

Bu çalıșma kapsamında İzmir ve çevresinin 3-B kabuk hız yapısının yerel deprem tomografisiyle araştırılmıştır. Bu doğrultuda 2008-2014 yılları arasında 44 istasyon tarafından kaydedilen 1723 deprem kaydı analiz edilmiştir. İncelenen depremler arasından düşük RMS ve yüksek faz okumasına sahip 773 depreme ait toplam 7556 P- ve 6381 S-fazı seçilmiştir. Tomografi bulgularından hareketle Vp ve Vp/Vs modellerine ait yatay ve düşey 3-B derinlik kesitleri oluşturulmuştur. Moho sınırının $24 \mathrm{~km}$ derinde olduğu belirlenmiştir. Üst mantoya kadar kabuk içinde 4 farklı sismik hız zonunun varlığ 1 tespit edilmiştir. 1.katman (üst kabuk) 0-7 km kalınlıkta $\mathrm{Vp}<5 \mathrm{~km} / \mathrm{sn}, 2 . \mathrm{katman}$ (orta katman) 7-15 km derinlikler arasında $\mathrm{Vp} \sim 6,2$ $\mathrm{km} / \mathrm{sn}$, 3.katman (alt kabuk) $9 \mathrm{~km}$ kalınlıkta $(15-24 \mathrm{~km}) \mathrm{Vp} \sim 6,2-7,4 \mathrm{~km} / \mathrm{sn}$ arasında, kabuk-manto sinırı altında yer alan 4.katman ( $\mathrm{h}>24 \mathrm{~km}) \mathrm{Vp}>7,7 \mathrm{~km} / \mathrm{sn}$ olarak belirlenmiştir. Çalışma alanında 3 farklı hız modeli gözlenmiştir. Bunlar; 1) Düşük Vp ve düşük $V p / V s$, 2) Düşük Vp ve yüksek Vp/Vs, 3) Yüksek Vp ve yüksek Vp/Vs şeklindedir. Yüksek gaz ve $1 \mathrm{~s}$ içeren jeotermal alanların düşük $\mathrm{Vp}$, düşük Vp/Vs modeli ile temsil edildiği gözlenmiştir. Seferihisar Fay Zonu ve Karşıyaka Fay Zonu arasında kalan geniş bir bölgede henüz keşfedilmemiş potansiyel jeotermal alanlar olabileceği sonucuna ulaşıllmıştır.

\section{3-D crustal velocity structure of izmir and surroundings}

\section{H I G H L I G H T S}

- $\quad$ First attempt to determinate seismic velocity structure of Izmir, western Turkey

- $\quad$ Revealing of Izmir geothermal potential

- Application of local earthquake tomography method to geothermal fields

Article Info

Received: 30.03.2016

Accepted: 27.02.2017

DOI:

$\overline{110.17341 / \text { gazimmfd.337620 }}$

Keywords:

3-D local earthquake

tomography,

aegean region,

izmir,

crustal velocity structure

\section{ABSTRACT}

3-D crustal velocity structure of Izmir and surroundings has been investigated in the frame of this study by using Local Earthquake Tomography. For this purpose, 1723 earthquakes that recorded by 44 stations from 2008 to 2014 have been analyzed. We selected 773 earthquakes which have 7556 P- and 6381 S-phase considering low RMS and high phase reading. We formed 3-D horizontal and vertical depth cross-sections for $\mathrm{Vp}$ and $\mathrm{Vp} / \mathrm{Vs}$ models based on tomographic results. Moho boundary was detected at $24 \mathrm{~km}$ depth in the study area. We have identified four different seismic velocity zones down to upper mantle: Thickness of first the layer (called as upper crust) is $\sim 7 \mathrm{~km}$ and has $\mathrm{Vp}<5 \mathrm{~km} / \mathrm{sec}$, second (middle) layer is about between 7-15 km depths having $\mathrm{Vp} \sim 6.2 \mathrm{~km} / \mathrm{sec}$, thickness of the third one called as lower crust is $\sim 9 \mathrm{~km}$ (located from 15 to $24 \mathrm{~km}$ ) depth representing $\mathrm{Vp} \sim 6.2-7.4 \mathrm{~km} / \mathrm{sec}$, and the fourth and last one located beneath crustmantle boundary is detected deeper than $24 \mathrm{~km}$ depths showing greater than $\mathrm{Vp}, 7.7 \mathrm{~km} / \mathrm{sec}$. Three different velocity models were observed in the study area. These are; 1) Low Vp and low Vp/Vs, 2) low Vp and high $\mathrm{Vp} / \mathrm{Vs}, 3$ ) high Vp and high Vp/Vs. High Vp and high Vp/Vs values are observed at different depths of Urla and Seferihisar regions located at the south of the study area. We conclude that new potential geothermal areas which are not discovered yet, may exist in wide area between Seferihisar Fault Zone and Karsiyaka Fault Zone.

\footnotetext{
*Sorumlu Yazar/Corresponding Author: orhan.polat@deu.edu.tr / Tel: +90 2323017266
} 


\section{GIRISŞ (INTRODUCTION)}

Farklı sistemler denetiminde harekete geçme potansiyeli yüksek aktif faylarla çevrili olan İzmir ve yakın çevresinin üç-boyutlu (3-B) yeraltı sismik hız yapısının ortaya konmasını amaçlayan bu çalışma kapsamında Yerel Deprem Tomografisi (YDT) yöntemi kullanılmıştır. Özellikle Vp/Vs sonuçlarından hareketle litoloji hakkında doğru ve güvenilir sonuçlar üretmesi nedeniyle son on yılda dünyada artan sayıda kullanımı olan bir yöntem haline gelmiştir. Ülkemizde, 250 istasyon ile kaydedilen 3949 deprem analiz edilerek Marmara bölgesinin yeraltı sismik hız yapısı incelenmiştir [1]. TOMOG3D [2] algoritmasının kullanıldığı söz konusu çalışmada, düşük $\mathrm{Vp}$ ve $\mathrm{Vp} / \mathrm{Vs}$ oranlarının sedimanter birimlerle ilişkisi ortaya konmuştur. Erzincan dolaylarında yapılan bir başka YDT çalışmasında ise 58 istasyon tarafindan kaydedilen 1025 deprem verisi kullanılmıştır [3]. SIMUL2000 [4] yazılımının kullanıldığı bu çalışmada havzanın 15 km'ye kadar sismik hız yapısını araştırılmış, ilk 2-3 km derinliklerde Neojen yaşlı sedimanların hakim olduğu ortaya konmuştur. Koulakov vd. [5]; Kuzey Anadolu Fayının Batı kolunda 41 istasyon tarafindan kaydedilen 1140 depremi LOTOS [6] algoritmasıyla incelemiş, $20 \mathrm{~km}$ derinliğe kadar sismik hız yapısını ortaya koymuş ve sismisitenin yoğun olduğu bölgelerde hızlarda azalma olduğunu vurgulamışlardır. Kaypak ve Gökkaya [7]; jeotermal aktivitenin yoğun olduğu Denizli bölgesinde 24 istasyon tarafindan kaydedilen 635 deprem verisini analiz etmiş ve yüzeye yakın bölgelerdeki yüksek Vp/Vs oranlarının, sıvı içerikli kırıklar ya da yüksek Sıvı basıncı ile ilişkisini ortaya koymuştur. Öte yandan YDT yöntemi dışında ülkemizin farklı bölgelerinde yapılan tomografik çalışmalar da mevcuttur. Cambaz ve Karabulut [8]; Love dalgası grup hızı tomografisi ile Marmara Bölgesinde kabuk kalınlığının 30 km'den az olduğunu belirlemiştir. Tezel vd. [9]; alıcı fonksiyon analizi yöntemiyle Batı Anadolu kabuk hız yapısını araștırmıs ve Ege Bölgesinde Moho süreksizliğinin 25-35 km derinlikler arasında olduğunu ortaya koymuştur. Mutlu ve Karabulut [10] tarafından yapılan anizotropi çalışmasında Türkiye'deki kabuk kalınlığının doğudan $(\sim 40 \mathrm{~km})$ batıya $(\sim 25 \mathrm{~km})$ azaldığ $\breve{1}_{1}$ tespit edilmistir. Salaun vd. [11]; yüzey dalgası tomografisi kullanarak 3-B S- dalga hızı modelini ortaya koymuş ve üst-manto için 80-200 km derinlikler arasında düşük hız zonu belirlemişlerdir. Karabulut vd. [12]; Batı Anadolu'da İzmir-Ankara sütur zonu altında $32 \mathrm{~km}$, Menderes Masifi altında ise $\sim 25 \mathrm{~km}$ derinliklerde düşük hız zonuna sahip uzun dalga boylu değişimler, rapor etmişlerdir. $\mathrm{Bu}$ çalışmada; 2008-2014 tarihleri arasında 44 istasyon tarafindan kaydedilen 1723 yerel deprem verisi LOTOS algoritması ile analiz edilmiş, yanal ve düşey yöndeki kesitler ile $25 \mathrm{~km}$ derinliğe kadar İzmir ve çevresi için 3-B sismik hız yapısı belirlenmiş, bulgular tektonik unsurlar ile ilişkilendirilmiştir.

\section{TEKTONIK VE JEOLOJIKK YAPI (TECTONIC AND GEOLOGICAL STRUCTURE)}

Alp-Himalaya kuşağında [13] bulunan Türkiye'de, sismik etkinliği yüksek [14] birçok sismik zon bulunmaktadır [15]. 734
Bölgenin tektonik özellikleri incelendiğinde Arabistan, Afrika ve Avrasya levhalarının Anadolu Bloğu'nun hareketinde önemli bir rol oynadığı görülmektedir (Şekil 1a). Doğu Anadolu Fay Zonu (DAFZ) ve Kuzey Anadolu Fay Zonunun (KAFZ) kinematik özellikleri [16], doğuda Karlıova civarlarından başlayarak arada sıkışan [17] Anadolu Bloku'nun batıya doğru kaçışına [18] neden olmaktadır. Yay-ardı açılma modeli Ege yayının, dalan levhanın geriye çekilmesi sonucu güneye hareketini ve Ege'de K-G yönlü genişlemeyi açıklamaktadır [19]. Bu tektonik hareketler sonucu Türkiye'nin batısında incelen bir kabuk yapısı gözlenmektedir [20]. Karmaşık tektonik sistemlerin olduğu Batı Anadolu'da, K-G yönlü açılma rejimi etkisiyle D-B uzanımlı normal faylar ve KD-GB uzanımlı doğrultu atımlı faylar, çalışma alanında deprem üreten en önemli tektonik unsurlardır [21]. Ege Bölgesinin ve Batı Anadolu'nun ülke ekonomisine yaptığı katma-değer ve nüfus yoğunluğu bakımından en önemli illeri arasında başı çeken İzmir'i ve yakın çevresini etkileyen en önemli diri faylar; Menemen Fay Zonu (MFZ), İzmir Fay Zonu (IFZ), Orhanl1-Tuzla Fay Zonu (OFZ), Seferihisar Fay Zonu (SFZ) ve Gülbahçe Fayı (GF)'dır [22]. Bu faylar, aynı zamanda jeotermal enerji [23] açısından ülkemizde ayrı bir konumda olan İzmir çevresindeki jeotermal alanları da denetlemektedir [25]. Bu alanlara ilişkin bilgiler Tablo 1'de verilmiştir [26]. Aliağa, Balçova, Çeşme, Menemen, Seferihisar ve Urla çevreleri en İzmir'in en önemli jeotermal bölgeleri olarak ön plana çıkmaktadır. İzmir ve çevresinde üç tektonik kuşak yer almaktadır. Bu kuşaklar batıdan doğuya doğru Karaburun Kuşağı, İzmir-Ankara Zonu ve Menderes Masifidir. Menderes Masifi Eosen yaşlı metamorfiklerden, İzmir-Ankara Zonu KampaniyenDaniyen yaşlı tortul kayalar ve volkanik malzemelerden, Bornova Karmaşı̆̆ 1 filiş matriksler içerisinde bulunan kireçtaşları ile oluşmuştur. Karaburun Kuşağı [27], İzmirAnkara Zonunun platformunu oluşturmuş ve Bornova Karmașığı içine ilerleyerek Izmir-Ankara Zonu içine itilmiştir. Karaburun yarımadasında Triyas'dan Alt Kretaseye kadar kalın ve sı ̆ denizel karbonat istifi bulunmaktadır [28]. Nüfus yoğunluğunun fazla olduğu İzmir körfezi ve çevresinde alüvyon birimler, çalıșma alanının kuzeyinde ve batısında neojen yaşlı volkanikler, doğusunda kor volkan kompleksleri [29] ve çalışma alanının genelini temsilen bölgede Bornova Filiş Zonu [30] bulunmaktadır (Şekil 1b) (Kısaltmalar: DB: Doğanbey Burnu, Gülbahçe Fayı (GF), GK: Gülbahçe Körfezi, İzmir Fay Zonu (İFZ), KFZ: Karşıyaka Fay Zonu, KY: Karaburun Yarımadası, Menemen Fay Zonu (MFZ), Orhanl1-Tuzla Fay Zonu (OFZ), SK: Sığacık Körfezi, Seferihisar Fay Zonu (SFZ), Spil D.: Spil Dağı, SY: Seferihisar Yükselimi, UA: Uzunada, UFZ: Uzunada Fay Zonu. Jeotermal alanlar: 1) AJS: Aliağa jeotermal sistemi, 2) BJS: Balçova jeotermal sistemi, 3) ÇJS: Çeşme jeotermal sistemi, 4) MJS: Menemen jeotermal sistemi, 5) Seferihisar jeotermal sistemi, 6) USS: Urla sicak su çıkışları).

\section{VERİ VE YÖNTEM (DATA AND METHOD)}

$\mathrm{Bu}$ çalışma kapsamında homojen istasyon dağılımı elde edebilmek için farklı ajanslara ait kataloglar birleştirilmiştir. 
Tablo 1. İzmir ve çevresinde yer alan önemli jeotermal alanlar [26]

(Significant hydrothermal areas in Izmir and surroundings)

\begin{tabular}{lllll}
\hline No & Bölge & Jeotermal Alan & Boylam $\left({ }^{\circ}\right)$ & Enlem $\left(^{\circ}\right)$ \\
\hline 1 & \multirow{2}{*}{ Aliağa } & Samurlu & 26,9896 & 38,7643 \\
2 & Balçova & Ilıca & 26,9129 & 38,8137 \\
& & Merkez & 27,0352 & 38,3888 \\
3 & Çiftlikköy & 26,2796 & 38,2879 \\
& \multirow{2}{*}{ eş̧me } & Ilıca & 26,3638 & 38,3064 \\
& & Sifne & 26,3988 & 38,3209 \\
\multirow{2}{*}{4} & \multirow{2}{*}{ Menemen } & Bozköy & 27,0076 & 38,6445 \\
& & Deniz & 26,9879 & 38,6635 \\
& & Ilıcagöl & 26,9974 & 38,6565 \\
\multirow{2}{*}{5} & Seyrek & 26,9173 & 38,5500 \\
& \multirow{2}{*}{ Seferihisar } & Kanliada & 26,8813 & 38,0246 \\
& & Karakoç & 26,8930 & 38,1585 \\
\multirow{2}{*}{6} & \multirow{2}{*}{ Urla } & Kelalan & 26,9718 & 38,2013 \\
& & Gülbahçe & 26,6410 & 38,3468 \\
& & İcmeler & 26,6791 & 38,3091 \\
\hline
\end{tabular}

Afet ve Acil Durum Yönetimi Başkanlığı (AFAD) tarafından işletilen ve Türkiye deprem veri merkezi (TDVM) üzerinden deprem bilgilerine eş-zamanlı erişim sağlanabilen CMG6TD ve GMS-Plus [32] , AFAD-DEÜ ortaklığında kurulan ve CMG-5TD cihazlardan oluşan İzmirNET kuvvetli yer hareketi istasyonları [33], Atina Ulusal Gözlemevi (NOA) [34] tarafından işletilen ve ISC (International Seismological Center) [35] tarafinda katalog verileri yayınlanan CMG3ESP ve Boğaziçi Üniversitesi Kandilli Rasathanesi ve Deprem Araştırma Enstitüsü (KRDAE) [36] tarafindan işletilen ve ISC (International Seismological Centre) [35] tarafindan katalog verileri yayınlanan CMG-DM24 ve CMG-5TD'den oluşan, toplam 1723 deprem verisi tek bir katalog altında birleştirilmiştir. İzmir ve çevresindeki 44 istasyon verisi kullanarak yürütülen bu çalışmada en az 12 P- faz okuması yapılan (S- faz okumasındaki yetersizlikler sebebiyle bu faza herhangi bir koşul getirilmemiştir), RMS değeri 0,15'den küçük olan 773 depreme ait toplam 7556 Pve 6381 S-fazı kullanılmıştır (Şekil 2) (Kısaltmalar: D.B.G.: Demirköprü Baraj Gölü, M.A.: Midilli Adası, M.G.: Marmara Gölü, Sa.A.: Sakız Adası, Si.A.: Sisam Adası).

İlksel olarak Hypo71 [37] ile konumlandırılan tüm katalog (kırmızı) ve seçilmiş depremler (mavi) LOTOS [6] ile konumlandırılarak elde edilen depremlerin derinlik dağılımları Şekil 3'de gösterilmektedir. 1723 deprem içeren tüm katalogdan belirli kriterler çerçevesinde 773 deprem seçilmiştir. Seçilen depremler genellikte İzmir ve yakın çevresinde kümelenmekte, deprem derinliklerinin 0-25 km arasında yoğunlaştığı gözlenmektedir. Depremler konumlandırılırken 6 tabakadan oluşan ve Vp hızları 4,1 $\mathrm{km} / \mathrm{sn}$ 'den $7,7 \mathrm{~km} / \mathrm{sn}$ 'ye değişen $1-\mathrm{B}$ sismik hız yapısı kullanılmıştır (Tablo 2). Bu çalışmada yerel deprem tomografisi yönteminde başarılı sonuçlar üreten LOTOS v12 [6] algoritması kullanılmıştır. Yöntem, yeraltı sismik hız yapısını belirlerken iki tabaka arasındaki hız değișimini sabit değil, bir hız gradyeni şeklinde tanımlamaktadır. Ayrıca model uzayı dışındaki depremleri kullanarak diğer tomografi programlarına göre daha geniş bir alan için çözüm yapabilmektedir [38].

Bu çalışma kapsamında Hypo71 [37] ile ilksel olarak elde edilen en büyük 1,5 sn civarlarındaki rezidüel değerlerinin, 3-B optimizasyon sonucu 0,5 sn'lerin altına düştüğü tespit edilmiștir. Başlangıçta 21297 adet P- fazına sahip tüm katalog Hypo71 [37] ile konumlandırılırken, en az 12 faz okumasına ve RMS değeri 0,15'den küçük olan 13937 faza ait 773 deprem LOTOS [6] ile tekrardan konumlandırılmış ve deprem lokasyonları iyileştirilmiştir (Şekil 4).

Tablo 2. Model çözümünde kullanılan 1-B sismik hız yapıs1 (1-D seismic velocity structure used in 1-D model solution) [39]

\begin{tabular}{ll}
\hline $\begin{array}{l}\text { Derinlik } \\
(\mathrm{km})\end{array}$ & $\begin{array}{l}\text { P Hız1 } \\
(\mathrm{km} / \mathrm{s})\end{array}$ \\
\hline$-1,0$ & 4,1 \\
1,5 & 4,2 \\
9,7 & 4,7 \\
12,7 & 6,2 \\
18,0 & 6,5 \\
21,7 & 7,5 \\
30,0 & 7,7 \\
\hline
\end{tabular}

\section{4. ÜÇ BOYUTLU HIZ YAPISI (THREE DIMENSIONAL VELOCITY STRUCTURE)}

3-B hız yapısının ortaya konmasına yönelik çalıșmalarda, model parametrelerinin hassasiyetini görmek için dama tahtası (checker-board) testi, sismik tomografide yaygın olarak kullanılan bir yöntemdir. Bu deneylerde araştırma bölgesi (hacmi) belirli sayıda dikdörtgen prizmalara bölünür ve bu prizmaların her birine ardıșık olarak yüksek ve düşük hız değerleri atanır. Bu şekilde oluşturulan hız modelinden sentetik seyahat zamanları hesaplanmaktadır. 

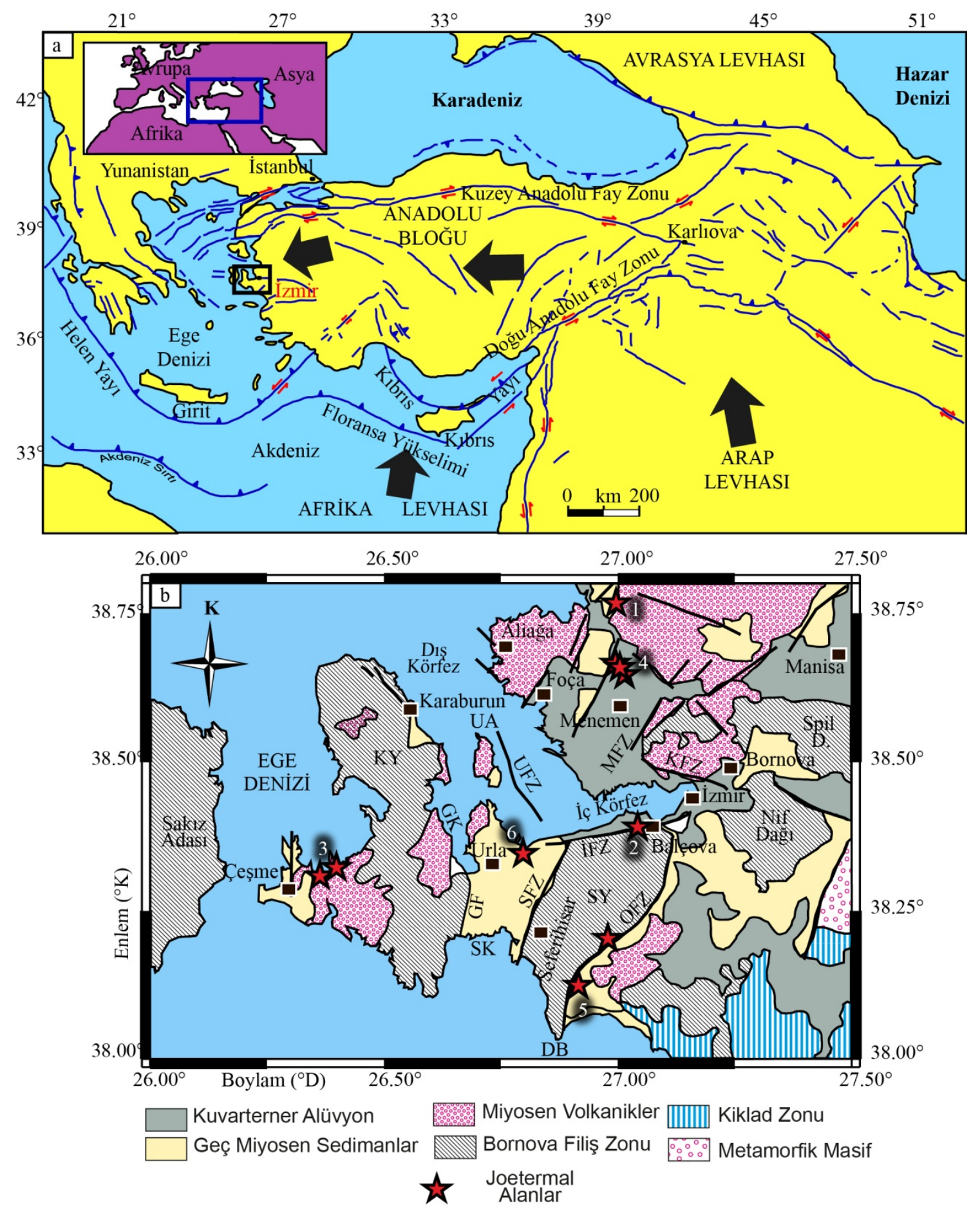

Şekil 1. a) Türkiye'nin tektonik haritası ve çalışma alanı [16], b) Çalışma alanının genel jeolojisi [31] ve önemli jeotermal alanlarının konumları

( a) Tectonic map of Turkey and study area b) Main geology of the study area and location of the important geothermal areas)

Bu sentetik seyahat zamanları tomografi ile işlenerek orijinal dama tahtası șeklindeki hız yapısının düzgün bir şekilde elde edilip edilmediğine bakılır. Eğer dama tahtası görünümlü deneysel hız yapısı elde edilmiyorsa, dikdörtgen prizmaların boyutları değiştirilerek yeni deneme yapılır. $\mathrm{Bu}$ işlem tomografi sonucu dama tahtası görünümünde bir sonuç verene kadar devam edilir. Yatay ve düşey eksendeki düğüm noktaları Şekil 5'de gösterilmektedir. Örnekleme aralığını 736 gösteren düğüm düzlemleri arasındaki hız yapısı, çalışma uzayı bloklara bölünür ve bu bloklar arasında hız geçiși ara değer bulma ile hesaplanarak elde edilir. Yatay düzlemde veri yoğunluğunun fazla olduğu İzmir ve çevresinde düğüm düzlemleri arasındaki mesafe $5 \mathrm{~km}$ iken, model dışında bloklardan geçen ışın sayısını artırmak için mesafe 10 km'ye çıkarılmıştır. Düşey düzlemde ise yatay düzlemdeki kisasların yanında, $20 \mathrm{~km}$ ye kadar $1 \mathrm{~km}, 20 \mathrm{~km}$ 'den daha 


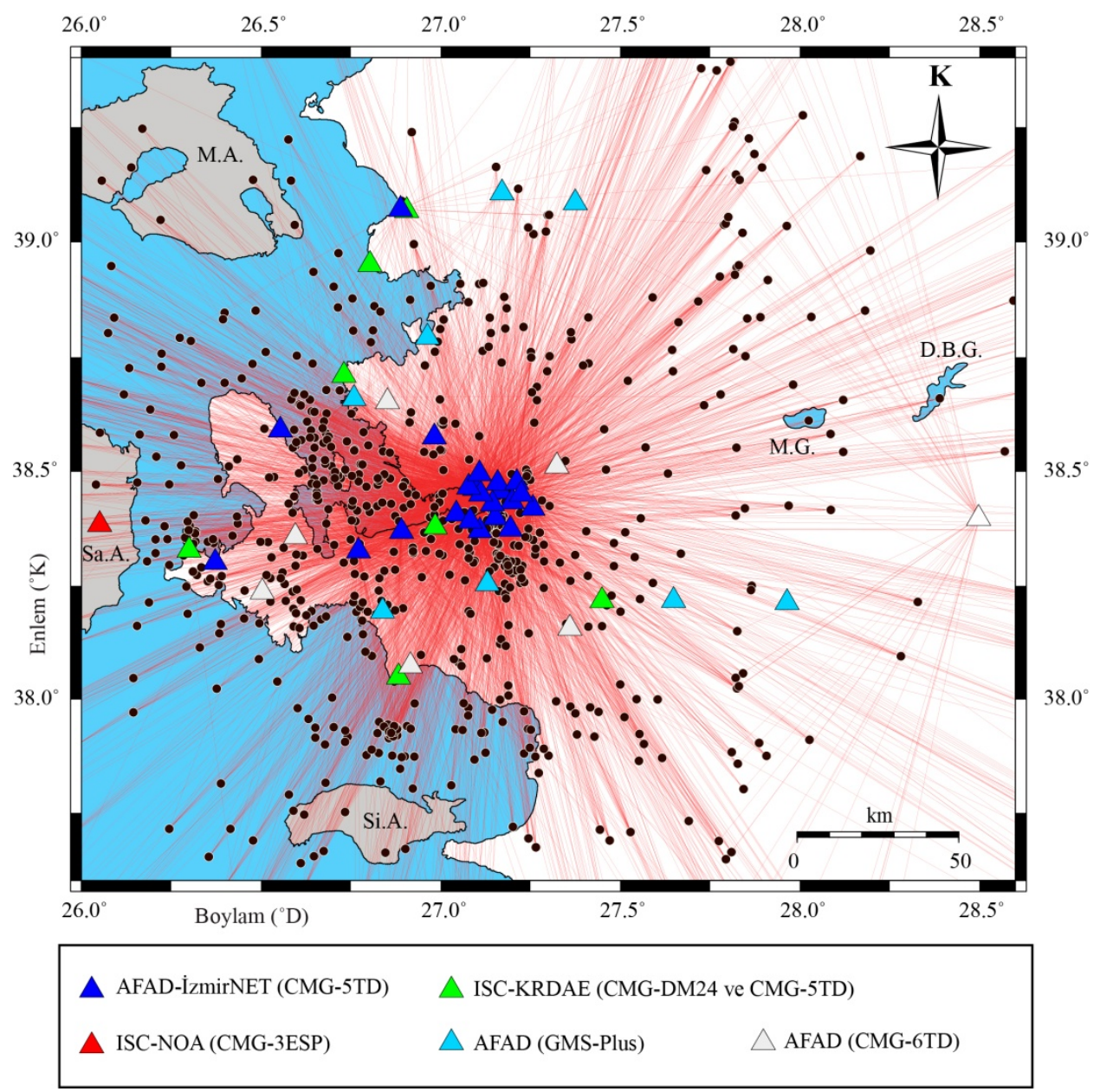

Şekil 2. AFAD, ISC, NOA ve KRDAE kataloglarından elde edilen 44 istasyon tarafından kaydedilen 773 seçilmiş depremin dağılımı ve 1 şın yolları

(Ray paths and distribution of 773 selected events recorded by 44 stations from the AFAD, ISC, NOA and KOERI)

derinlerde ışın sayısını artırmak amacıyla düğüm düzlemleri arasındaki mesafe 2 km’ye çıkarılmıştır. Dama tahtası testi sonuçlarına bakıldığında, P- hızları \%-15'den \%+15’e kadar değişen, hız değişimleri arasında $5 \mathrm{~km}$ boşluk bırakılarak oluşturulan boyutları $20 \times 20 \mathrm{~km}^{2}$ olan modelde çözünürlük İzmir ve çevresi için yüksektir (Şekil 6) (Açıklama: Ardışık olarak pozitif ve negatif hiz değerleri ile arasında $5 \mathrm{~km}$ boşluk bırakılarak $\left(20 \times 20 \mathrm{~km}^{2}\right)$ kurgulanmıștır. Siyah kesikli çizgiler çözünürlüğü yüksek olan alanı göstermektedir). Çözünürlük diğer tomografik çalışmalarda da olduğu gibi model alanının sınırlarına ve derinlere doğru deprem ve ışın yoğunluğunun zayıflaması nedeniyle azalmaktadır. Güvenilir alanlar kalın kesikli çizgi ile yatay tomografik kesitlerde gösterilmiştir (Şekil 6-7). Tomografik hesaplamalarda önemli bir diğer parametre sönüm faktörüdür. Farklı sönüm değerleri ile tek yineleme adımından oluşan denemeler yapılmış ve veri-model değişintisi dikkate alınarak en uygun sönüm faktörü 30 olarak belirlenmiştir. Dama tahtası sonuçları ile yatay kesitlerin uyumu karşılaştırıldığında İzmir ve çevresi için yapılan yorumların gerçekçi olduğu görülmüştür. Sadece İzmir'in Batısında, güneybatısında ve güneydoğusundaki bazı küçük alanlarda çözünürlüğün düşük olduğu gözlenmiştir. Yorumlar İzmir ve yakın çevresini kapsayan yüksek çözünürlük sınırları dahilindeki alan için yapılmıştır. YDT yöntemi [40] ile jeotermal aktivitenin yoğun olduğu bölgelerde [41] yapılan çalışmalarda [42] hız değişimine ilişkin karakteristik sismik modeller gözlenmiştir [43]. İzmir'in en önemli jeotermal sistemlerini içeren bölgelerde yapılan 3-B YDT çalışmasında da literatür ile uyumlu benzer sismik modeller gözlenmiş, yatay ve düşey hız değişimi kesitlerinden gözlenen bulguların tektonik unsurlar ve litolojiyle uyumlu olduğu tespit edilmiştir (Şekil 7, 8). İzmir ve çevresinde $16 \mathrm{~km}$ derinliğe kadar elde edilen yatay kesitler, P- dalgası ters çözümü için başlangıç modeli olarak tekdüze bir hız modeli kullanarak $\pm \% 15$ 'lik değişim ile hız değişimlerini ortaya koymaktadır. Siyah kesikli çizgiler çözünürlüğü yüksek olan alanı göstermektedir (Şekil 7) (Kısaltmalar: Krf: Körfez, ZBFZ: Zeytindağ-Bergama Fay Zonu). $0 \mathrm{~km}$ derinlikli yüzey yatay derinlik kesiti incelendiğinde Aliağa, Balçova, Çeşme, Menemen, Seferihisar, Urla jeotermal alanlarında negatif P- hızı değişimi dikkat çekmektedir. Seferihisar yükselimi, Spil ve Nif Dağları boyunca gözlenen yüksek hızlar Bornova filiş zonu ile ilişkilidir. Foça civarında gözlemlenen yüksek hızlar ise Miyosen volkaniklerden kaynaklanmaktadır. 

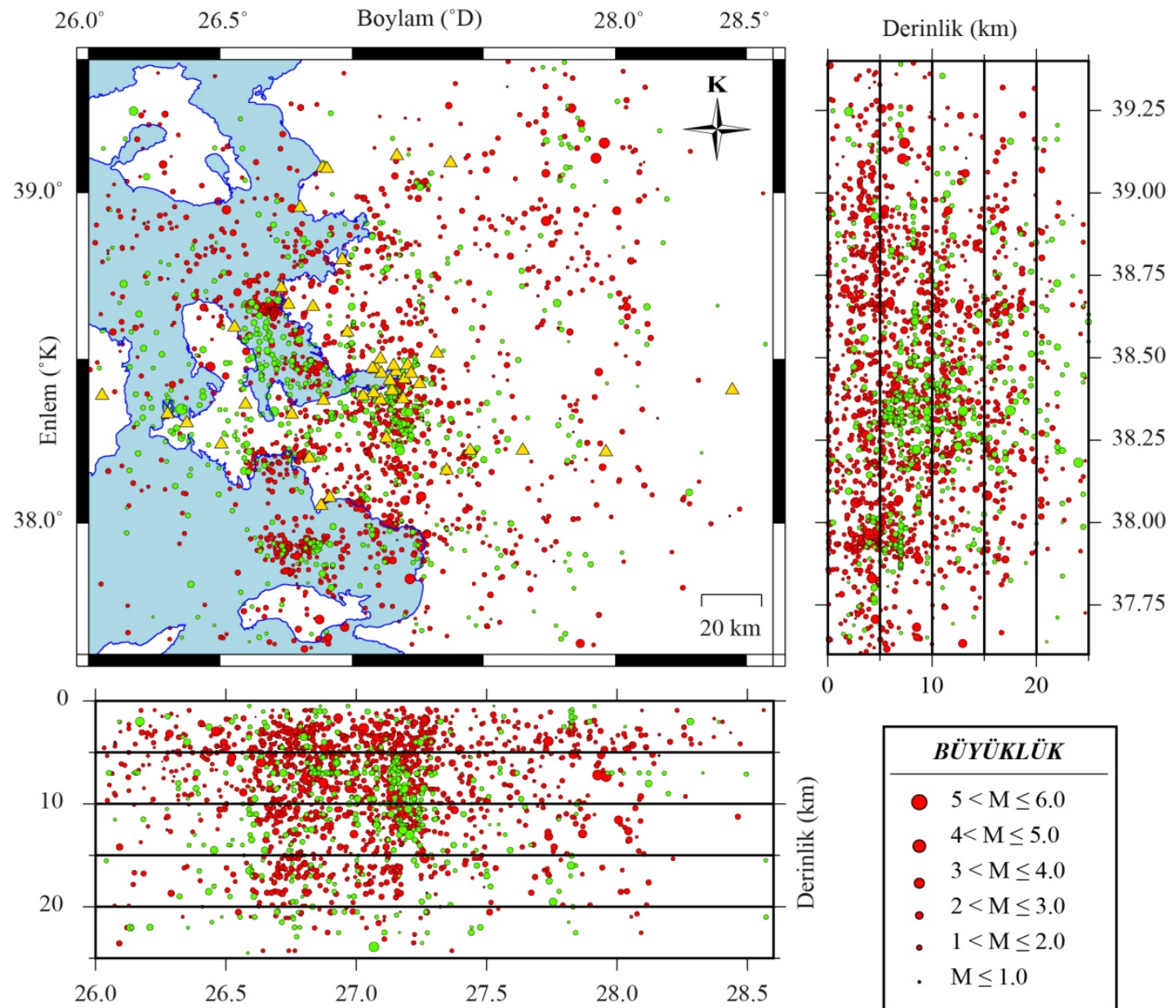

0

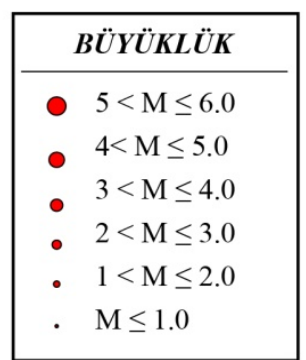

Şekil 3. Tüm katalog (kırmızı) ve seçilen (yeşil) depremlerin derinlik dağılımları (Depth distribution of all catalog (red) and selected (green) earthquakes)

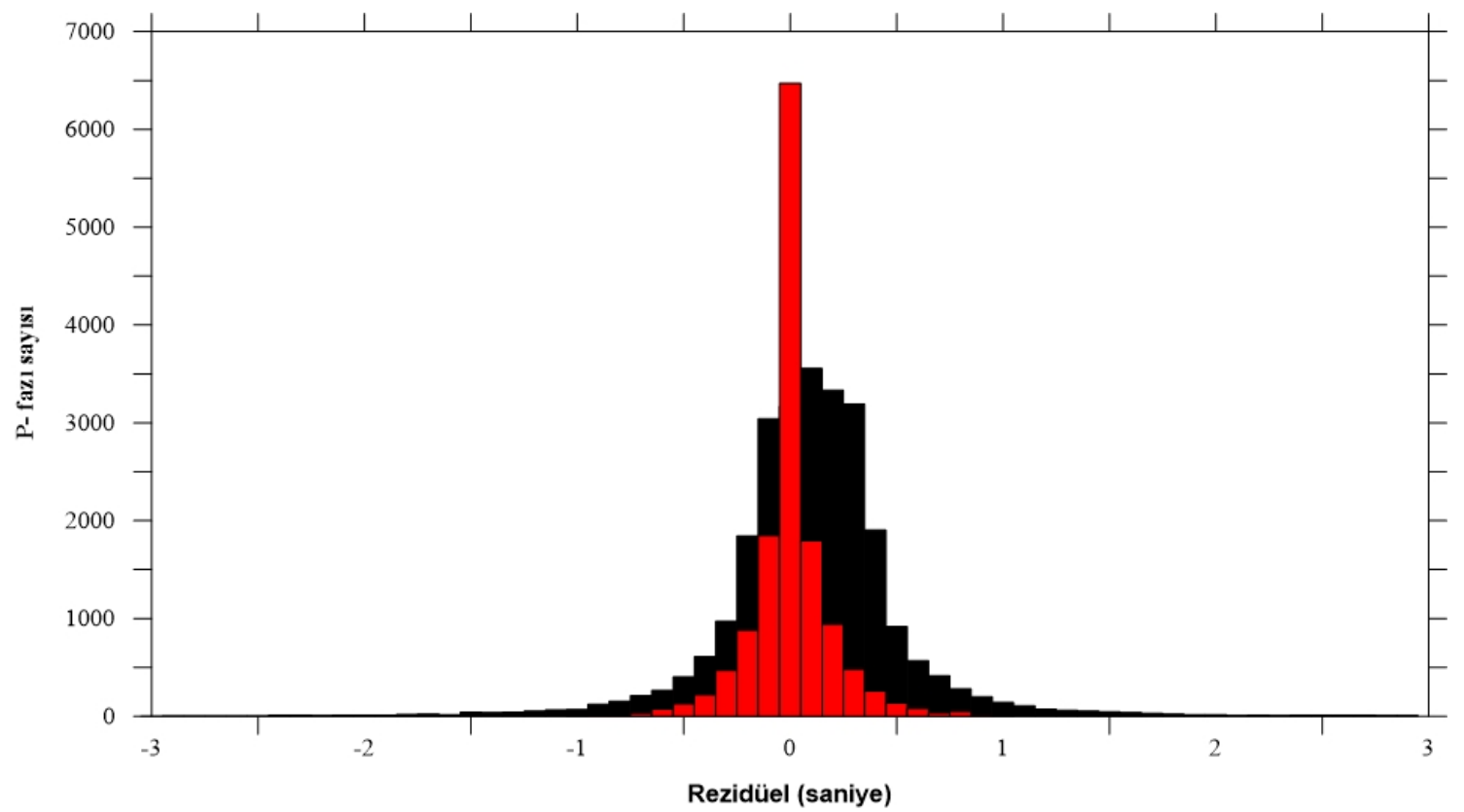

Şekil 4. Hypo71 [37] (Siyah) ve LOTOS v12 [6] (Kırmızı) ile konumlandırılan depremlerin P-fazı rezidüel değișimleri (P-phase residual variation of earthquake location with Hypo71 (Black) and LOTOS v12 algorithm (Red)) 


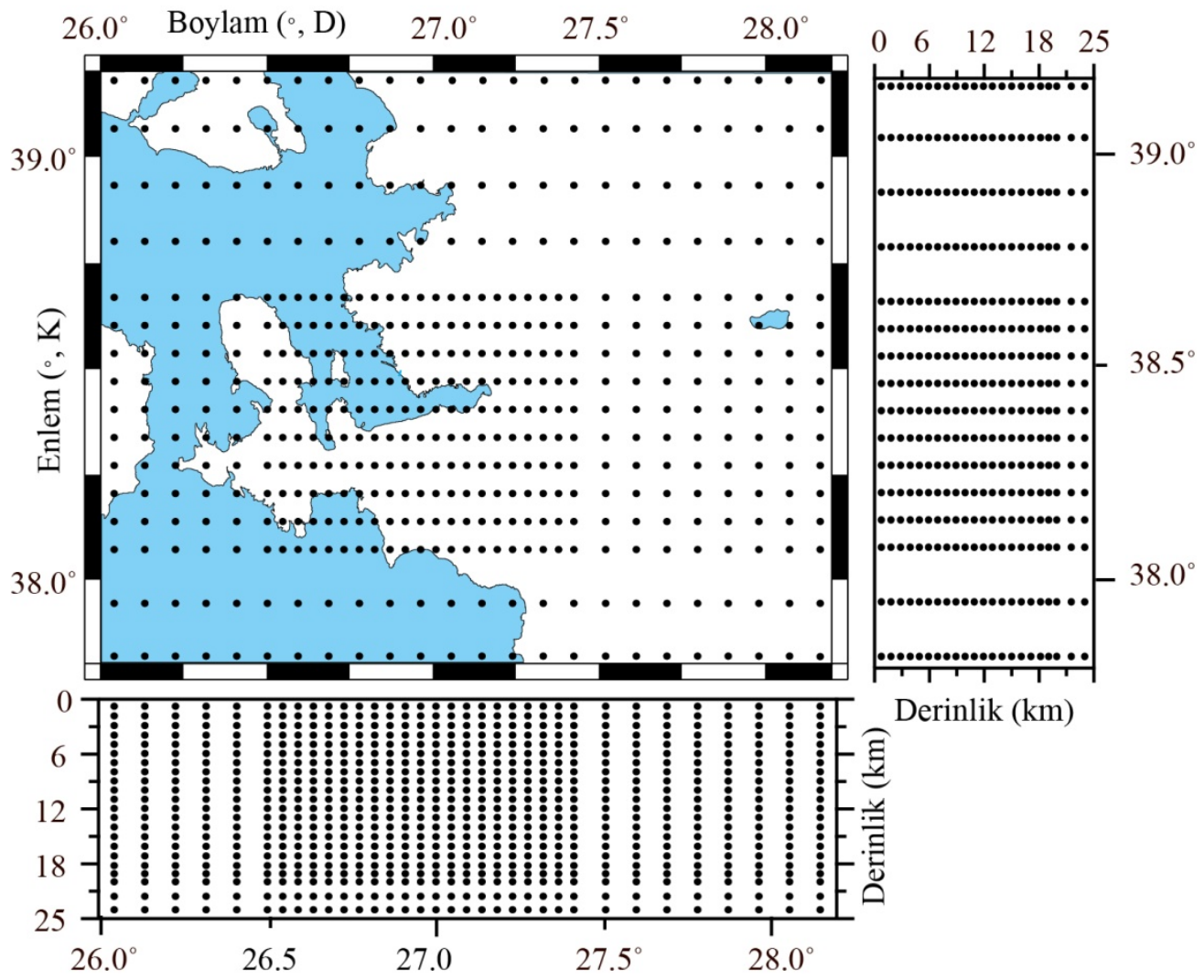

Şekil 5. Yatay ve düşey düzlemdeki düğüm düzlemlerinin dağılımı

(Distribution of nodes in horizontal and vertical planes)

İzmir iç körfez ve şehir merkezinde gözlemlenen negatif anomaliler bu yerleşim yerlerinde konumlanmış Kuvarterner alüvyonlar ile uyumludur (Şekil 7) [29]. 4 km derinlikli sı kesitte, İzmir iç körfezin doğusu ve Seferihisar yükseliminde gözlemlenen pozitif anomaliler (Şekil 7) Bornova Filiş Zonu ve neojen yaşlı volkaniklerle ile ilişkilidir [29]. Bu dağılımlar, yüzeye doğru sokulum yapmış magmatik kayaçlardan da kaynaklanmaktadır [44] (Şekil 8). Öte yandan $4 \mathrm{~km}$ derinlikli yatay kesitte Çeşme-Urla arası ve Aliağa çevresinde [45] gözlenen negatif değişimlerin, bölgede yürütülen araştırmalarda rapor edilen etkin jeotermal aktivite ile ilişkili olduğu düșünülmektedir [46]. Düşey kesitlerde 1 no'lu profilin GB uç kesiminde yer alan ÇJS yakınında, yüzeyden başlayarak derine doğru devam eden düşük hız anomalilerin varlığ 1 teyit edilmiştir (Şekil 8). İzmir körfezi içinde Uzunada civarında $20 \mathrm{~km}$ derinliğe kadar devam eden negatif anomaliler (Şekil 7, Şekil 8'da 2.profil) bölgedeki kırık zonları [30] ve bu zonlar boyunca transfer edilen akışkan içeriği ile ilişkilidir [47]. Hem 0 km, hem de $4 \mathrm{~km}$ yatay derinlik kesitlerinde Doğanbey Burnu (DB) güneyinde, OFZ tarafından üretilen kümelenmiş yoğun deprem etkinliği mevcuttur. Bölgede hakim olan jeolojik birim, Bornova Filiş Zonu'dur [29]. Bu birim, denizel volkanik ve serpantin ihtivası nedeniyle düşük soğrulma özelliği gösterdiğinden yerkabuğunun bu derinliklerinde pozitif Vp anomalileri gözlenmiştir [41]. $8 \mathrm{~km}$ derinliğe ait yatay kesite genel olarak bakıldığında, İzmir Körfezi ve civarındaki hız değişimlerinin 2-6 km derinlik bandının aksine ağırlıklı olarak negatife döndüğ̈̈ görülmektedir.
Yukarıda da değinildiği üzere bu durum, İFZ boyunca gözlenen karmaşık tektonizma ve derinlere doğru devam eden akışkan varlığı tezini güçlendirmektedir. İFZ'nu temsil eden hız dağılımının yüzeyden $8 \mathrm{~km}$ derinliğe kadar pozitif, 8-18 km derinlikler arasında ise negatif dağılım gösterdikten sonra yine pozitif'e doğru değişen eğilim sergilediği tespit edilmiştir (Şekil 7, Şekil 8'de 4. profil). MJS ve AJS arasında kalan K-G uzanımlı bölgede jeotermal akışkan varlığından kaynaklı düşük hız değişimlerinin derinlere doğru devam ettiği gözlenmiştir (Şekil 7, Şekil 8). 12 ve 16 km derinlikli yatay kesitlerde düşük hız anomalilerinin, AJS, BJS, ÇJS, SJS, MJS ve USS gibi jeotermal sistemlerin çevresinde kümelendiği gözlenmektedir. İç körfezin batı kesiminde yatay kesitlerde gözlenen D-B yönlü pozitif hız değişimleri, düşey kesitlerde de belirgindir (Şekil 7, Şekil 8'de 3.Profil). BJS ve AJS arasındaki geniş bölgede negatif hız değişimleri mevcuttur. Yüzeyden itibaren gözlenen bu negatif anomalilerin nedeninin, jeotermal sistemin derin kökeniyle ilişkili olduğu düşünülmektedir (Şekil 7, Şekil 8'de 1. 2. 3. ve 4.profiller). OFZ boyunca gözlenen negatif anomaliler bu zon boyunca taşınan jeotermal aktivite ile uyumludur. Hemen hemen bütün yatay kesitlerde 26,1-27,8 boylamları arasında KD-GB istikametinde konkav şekilli dar bir band boyunca gözlenen yüksek hız değişimleri gözlenmektedir. KD-GB uzanımlı bu pozitif anomaliler, topoğrafik değişimler ve derinlerdeki yüksek basınçlı akışkanlarla ilgilidir [48]. Ayrıca Karaburun yarımadası ile Manisa'nın doğusu arasında kalan kesimde gözlenen hızlar erken Miyosen yaşlı Bornova fliş zonunun uzanımı [49] ile 

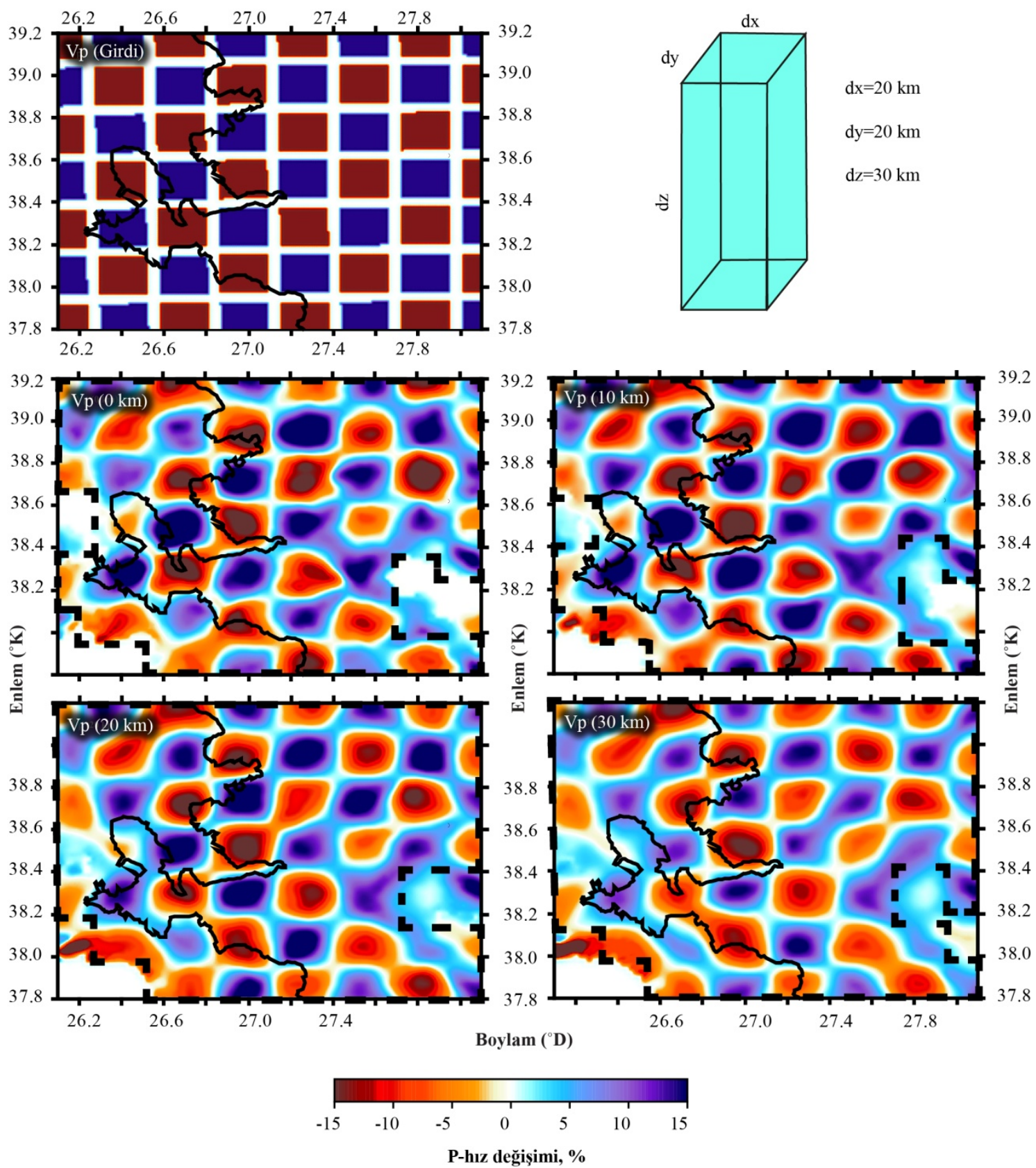

Şekil 6. 3-B hız tomografisi dama tahtası testi (Checkerboard test for 3-D velocity tomography)

uyumludur [50]. Kabuk-manto sınırının belirlenmesi için İzmir ve yakın çevresinde farklı jeofizik yaklaşımlar ile birçok çalışma yürütülmüştür. Ulugergerli vd. [51] Batı Anadolu'da jeoelektrik yöntemleri kullanarak yürüttükleri çalışmada açılma tektoniğine bağlı olarak kırılgan-elastik sınırın $\sim 25 \mathrm{~km}$ olduğunu ve tektonik rejimin kabuk kalınlığını azalttığı görüşünü savunmuşlardır. Pamukcu ve Yurdakul [52] Bouguer gravite verilerinin yardımıyla kabukmanto ara yüzeyini İzmir ve çevresinde $\sim 24 \mathrm{~km}$ olarak hesaplamışlardır. Ciftci vd. [53] Menderes Grabeninde yürüttükleri çalışmada kabuk-manto ara yüzeyinin 33 km'de konumlandığını vurgulamış ve 3 katmanlı hız modelini önermişlerdir. Komut vd. [54] Batı Anadolu'da yürüttüğü çalışmalarında İzmir ve çevresinde Moho derinliğini $\sim 26 \mathrm{~km}$ olarak belirtmişlerdir. Karabulut vd. [12] alıcı fonksiyon analizi yöntemi ile Menderes Masifinin kabuk kalınlığının $\sim 25 \mathrm{~km}$ olduğunu ve Batı'ya doğru kabuk kalınlığının inceldiğini vurgulamışlardır. Vanacore vd. [55] Ege bölgesindeki Moho derinliğinin $30 \mathrm{~km}$ 'den küçük olduğunu belirtmişlerdir. Delph vd. [56] Anadolu bloğu için ortalama S- dalgası kabuk kalınlığının ve hızının küresel ölçekte değerlendirildiğinde düşük olduğunu ve Isparta için kabuk kalınlığını $\sim 25 \mathrm{~km}$ olarak rapor etmişlerdir. Bu hız düşüklüğünün sebebini bazı bölgelerdeki yüksek sıcaklıklı sıvılar ile ilişkili olduğunu belirtmişlerdir. Kind vd. [57] Salıcı fonksiyon yöntemi ile kabuk kalınlığının Ege Bölgesinde $\sim 25 \mathrm{~km}$ olduğunu rapor etmișlerdir. Ozer ve Polat [39] İzmir ve çevresinin 1-B sismik hız yapısını belirlemek için yürüttükleri çalıșmada kabuk-manto geçişinin 23 km'de başladığını öne sürmüştür. 


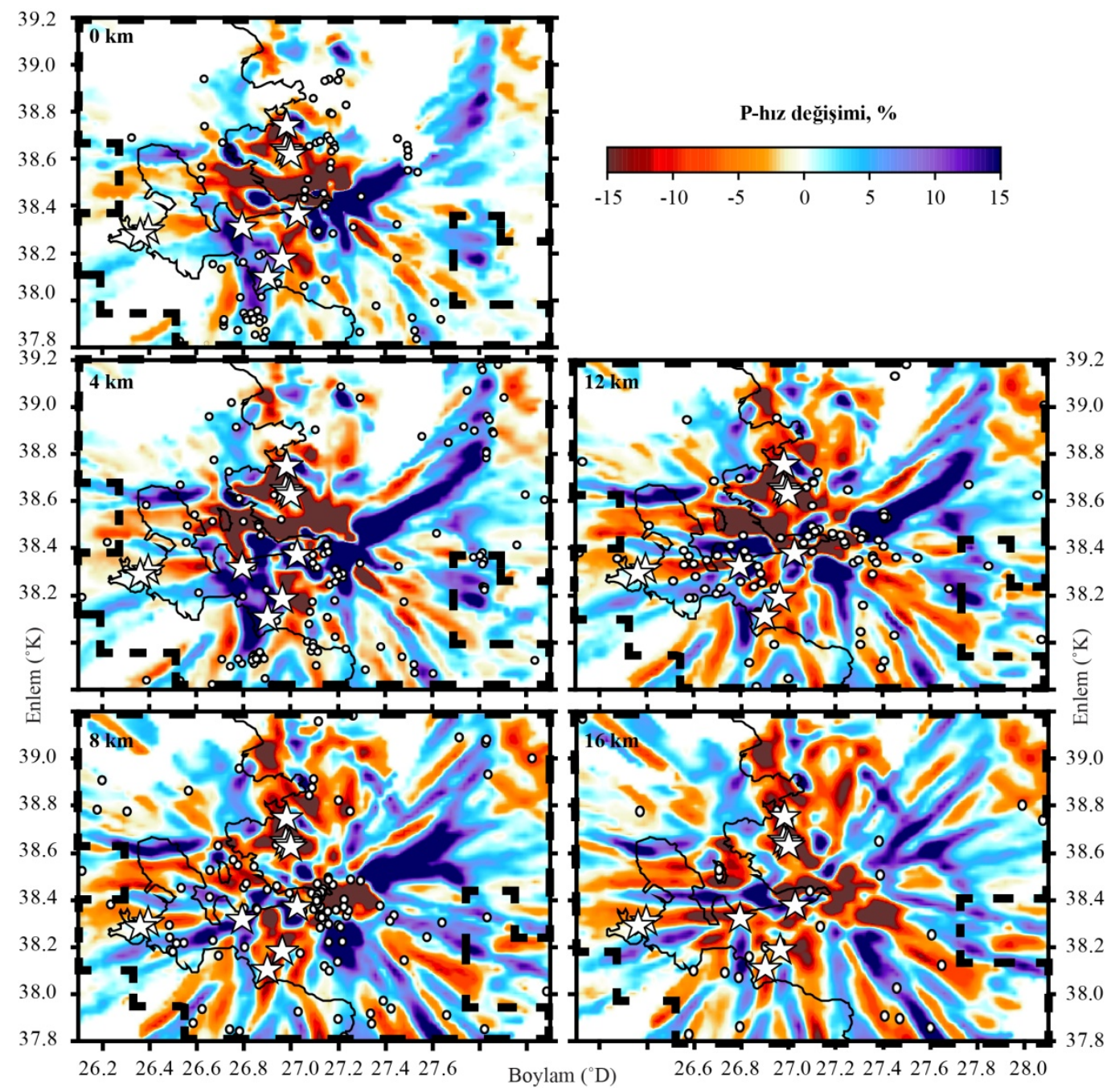

Şekil 7. İzmir ve çevresi için Vp tomografik yatay kesit sonuçları

(Vp tomographic horizontal section results for Izmir and surrounding area)

Hız değişimlerinin yanında, bu çalışma kapsamında gerçel $\mathrm{Vp}$ hızlarının ve $\mathrm{Vp} / \mathrm{Vs}$ modellerinin düşey kesitlerdeki dağ 1 lımı da incelenmiştir. Elde edilen sonuçlar, analizi yapılan depremlerin hiposantır dağılımları ile uyumlu olacak şekilde $25 \mathrm{~km}$ derinliğe kadar yorumlanmıştır (Şekil 9). Kabuk-üst manto hız sınırının yaklaşık $24 \mathrm{~km}$ derinde olduğu belirlenmiştir. İzmir Körfezi ve İFZ altında karmaşı hız yapılarının olduğu, $5 \mathrm{~km}$ kalınlığa ve $20 \mathrm{~km}$ genişliğe sahip düşük hız alanlarının varlığı ortaya konmuştur (Şekil 9'da 4 no'lu profil). Öte yandan kabuk içinde üst kesimlerine doğru sokulum yapan yüksek hızl yapılar da tespit edilmiştir. AJS, BJS, MJS ve İFZ'nin altında 1, 2 ve 3 no'lu profillerde derinlerden başlayıp $6 \mathrm{~km}$ sı̆̆ kesimlere kadar çıkan, $15 \mathrm{~km}$ kalınlığa ve $5 \mathrm{~km}$ genişliğe sahip yüksek $\mathrm{Vp}$ hız yapıları buna örnektir. İzmir Körfezini çapraz olarak GBKD yönlü kesen yaklaşık $140 \mathrm{~km}$ uzunluğundaki profillere ait düssey kesitler incelendiğinde, $\mathrm{Vp}$ hızlarının genelde 4 farklı katmana ait en küçük 4, en büyük $8,2 \mathrm{~km} / \mathrm{sn}$ arasında değiştiği belirlenmiştir. Yüzeyden yaklaşık $7 \mathrm{~km}$ derinliğe sahip üst kabuğu temsil eden ilk katmana ait düşük hızlar $(\mathrm{Vp}<5 \mathrm{~km} / \mathrm{sn})$ genç çökellere karşılık gelirken, bir alt katmanı temsil eden ve örneğin İzmir Körfezinde (Uzunada civarlarında) gözlenen daha yüksek hızlar ise Miyosen yaşlı birimleri temsil etmektedir. 2.katmanın, 7-15 km derinlikle arasında belirgin olduğu tespit edilmiștir. Bu katmanın üst kesimleri, havza tabanı geometrisinde (yüksek P-dalgası hızına sahip) magmatik sokulumların da etkisiyle heterojen bir görüntü vermektedir. Sismojenik zon olarak nitelendirilen ve depremlerin yoğun üretildiği bu kırılgan zonun tabanı $\sim 6,2 \mathrm{~km} / \mathrm{sn} \mathrm{Vp}$ hizına sahiptir. Daha derinlere (3.katman'a) doğru belirgin hız artışının görüldüğü katmanın kalınlığının ise ortalama $9 \mathrm{~km}$ olduğu belirlenmiştir. 15-24 $\mathrm{km}$ derinlikler arasında bulunan bu katman alt kabuk olarak nitelendirilmiştir ve 6,2-7,4 km/sn arasında değiş̧en P-dalga hızlarına sahip olduğu gözlenmiştir. Alt kabukta gözlenen bu yüksek hızlar, gabro [58] ve okyanusal kayaçlarla [59] ilişkilidir. Tüm düşey $\mathrm{Vp}$ hiz kesitleri bir arada değerlendirildiğinde kabuk-manto sınırının ortalama $24 \mathrm{~km}$ derinde dalgalı bir yüzeye sahip olduğu gözlenmiștir. $\mathrm{Bu}$ yüzey, bazı düşey kesitlerde $25 \mathrm{~km}$ derinliğe kadar inen, bazılarında da $20 \mathrm{~km}$ seviyelerine yükselen $10 \mathrm{~km}$ genişliğinde sokulumlara sahiptir. Çalışma alanında elde edilen bulgular sadece farklı Vp hız yapılarını değil, farklı $\mathrm{Vp} / \mathrm{Vs}$ modellerinin de olduğunu ortaya koymaktadır. 

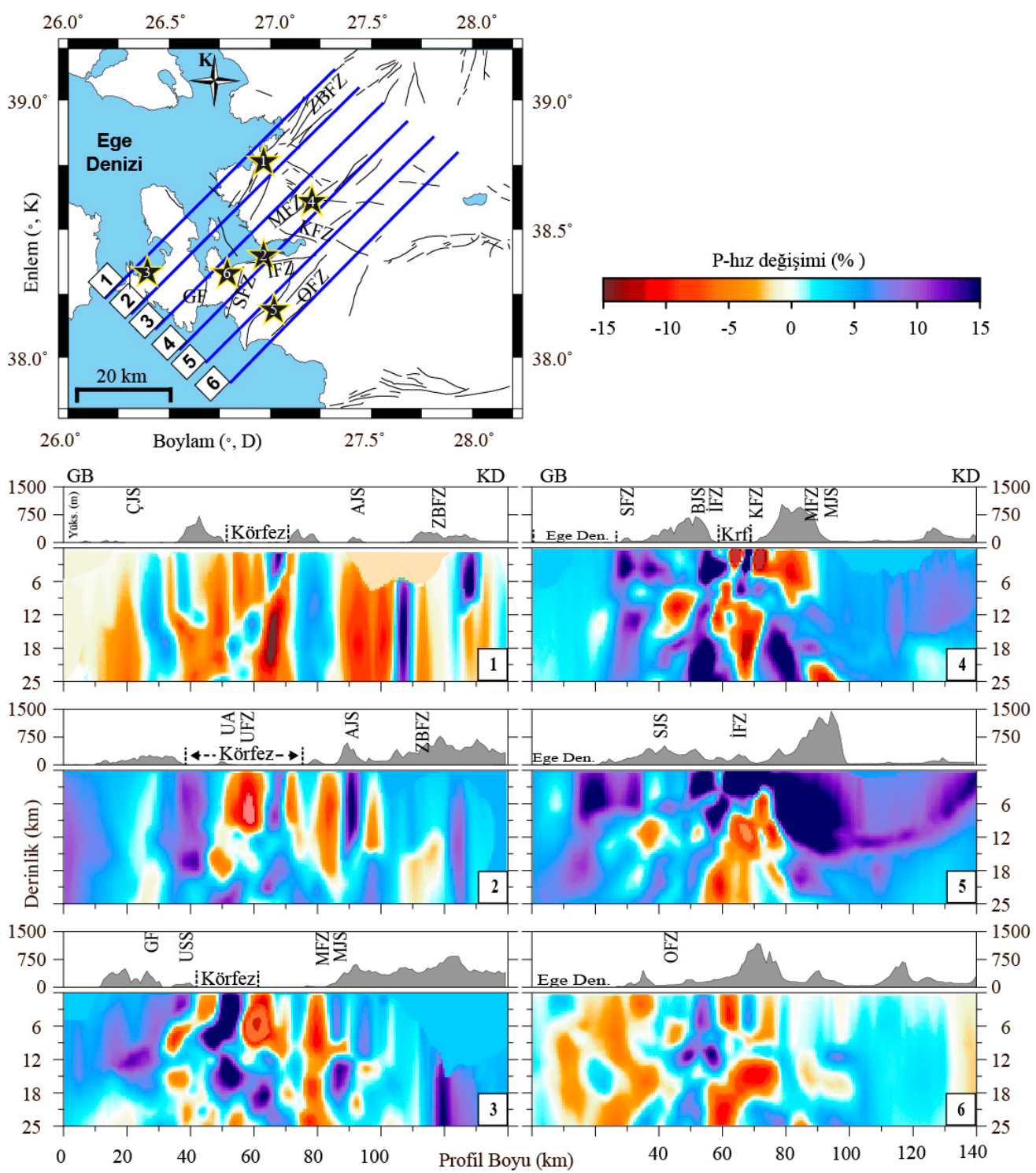

Şekil 8. İzmir ve çevresi için P-dalgası düşey kesit hız değişimi sonuçları

(Velocity perturbation results for P-wave vertical depth-cross section of Izmir and surrounding area)

$\mathrm{Vp} /$ Vs oranlarının P-dalga hızları ile birlikte yorumlanması kabuk yapısının içeriği (kırık, çatlak, gözeneklilik), mekanik ve petrolojik özellikleri ile ilgili yorumu kolaylaştırır [60]. Alt kabuğa inildikçe $\mathrm{Vp} / \mathrm{Vs}$ oranlarının düşmesi $(<1,7)$, sı̆̆ kesimlere doğru ise artması beklenir. Düşük $\mathrm{Vp} / \mathrm{Vs}$ oranı kayaçlardaki gaz içeriğinin yüksek, akışkan içeriğinin ise nispeten daha zayıf olmasıyla ilişkilidir. Düşük Vp/Vs anomalilerinin granitik kayaçlarının varlığı [41] ile ilişkili olduğu da rapor edilmiştir [48]. Yüksek Vp/Vs oranı, sı̆̆ derinliklerde bulunan yüzey kayaçlarındaki akışkan içeriğinin yüksek olmasının sonucudur [59]. Buna ek olarak sismolojik açıdan aktif olan ve kümelenme tipi deprem etkinliği gösteren sismojenik zonlarda da yüksek Vp [59] ve yüksek $\mathrm{Vp} / \mathrm{Vs}$ oranları rapor edilmiştir. [41]. Bu çalışma kapsamında 3 farklı hız modeli gözlenmiştir ve bu kombinasyonlara ait lokasyonlar Tablo 3'de verilmiştir.

1) Düşük $V p$, düşük $V p / V s$

2) Düşük $V p$, yüksek $V p / V s$

742
3) Yüksek Vp, yüksek Vp/Vs

\subsection{Düşük Vp, Düşük Vp/Vs (Low Vp, Low Vp/Vs)}

Bu tip anomaliler, genelde kayaç içeriğinde bulunan yüksek porozite ve gaz içeriği ile ilişkilidir [60]. Jeotermal bölgelerde ve volkanik alanlarda yapılan tomografi çalışmalarında sıklıkla rapor edilmektedir [61]. Çalışma alanında genelde ilk 10-15 km derinliklere kadar bu model yapısı baskın olarak gözlenmiştir. Özellikle jeotermal alanlarda (ÇJS, MJS, SJS), İzmir Körfezinde ve OFZ'da genelde düşük $\mathrm{Vp}(<5 \mathrm{~km} / \mathrm{sn})$, düşük $\mathrm{Vp} / \mathrm{Vs}(<1,6)$ oranları tespit edilmiştir. OFZ içinde yüzeyden yaklaşık $10 \mathrm{~km}$ derine doğru devam eden hız değerleri, Cumalı kaplıcalarının (SJS) bulunduğu jeotermal sisteme oldukça yakın bir konumda yer almaktadır. Bu nedenle bu modeli ortaya koyan yapının 10 km genişliğindeki derin kaynaktan beslendiğini ve yüzeye taşındığı sonucuna ulaşılmıştır. $10 \mathrm{~km}$ derinliğindeki oldukça düşük $\mathrm{Vp} / \mathrm{Vs}$ oranı $(\sim 1,5)$, bu kaynağın sıvı 
Tablo 3. Çalışma alanında farklı kombinasyonlarda gözlenen $V p$ ve $V p / V s$ anomalilerine ait özet gösterimi (Summarized representation related to $\mathrm{Vp}$ and $\mathrm{Vp} / \mathrm{Vs}$ anomalies that observed in different combinations)

\begin{tabular}{llll}
\hline \multirow{2}{*}{ Konum } & $\begin{array}{l}\text { Düşük Vp } \\
\text { Düşük Vp/Vs }\end{array}$ & $\begin{array}{l}\text { Düşük Vp } \\
\text { Yüksek Vp/Vs }\end{array}$ & $\begin{array}{l}\text { Yüksek Vp } \\
\text { Yüksek Vp/Vs }\end{array}$ \\
\hline BJS & $\checkmark$ & & \\
ÇJS & $\checkmark$ & & \\
MJS & $\checkmark$ & & \\
SJS & $\checkmark$ & & \\
OFZ & $\checkmark$ & & \\
ZBFZ & $\checkmark$ & & \\
Diş Körfez & $\checkmark$ & $\checkmark$ & \\
\hline AJS & & $\checkmark$ & \\
MFZ & & $\checkmark$ & \\
KFZ & & $\checkmark$ & \\
IFZ & & $\checkmark$ & \\
GF & & $\checkmark$ & \\
Foça & & $\checkmark$ & \\
Nif Dağ1 & & & \\
\hline SFZ & & & \\
\hline
\end{tabular}

içeriğinin yanı sıra gaz ihtivasıyla da ilişkili olduğunu ortaya koymaktadır (Şekil 9, 6. profil). UA civarında [30] da gözlenen bu tür benzer anomaliler, miyosen yaşlı volkanikler ve geç Miyosen sediman çökelleriyle ilişkilidir. Körfez içinde havza geometrisini ortaya koyan düşük hız yapıları gözlenmiştir. Bununla birlikte gerek İFZ, gerekse körfez içinde farklı derinliklerdeki $\mathrm{Vp}$ ve $\mathrm{Vp} / \mathrm{Vs}$ oranlarının aynı olmaması karmaşık bir tektonizmaya ve farklı litolojilerin varlığına işaret etmektedir (Şekil 9; 3-4-5. profiller). SFZKFZ arasında yer alan KD-GB doğrultulu 4.profil'e ait $\mathrm{Vp} /$ Vs kesitinde, 8-12 km derinlikler arasında $\sim 50 \mathrm{~km}$ uzunluğunda ve $\sim 4 \mathrm{~km}$ kalınlığında düşük $\mathrm{Vp} / \mathrm{Vs}$ oranı gözlenmiştir. $\mathrm{Bu}$ anomalinin bu bölgeler arasında henüz keşfedilmemiş yeni jeotermal alanların varlığına ilişsin önemli bir potansiyele sahip olduğu düşünülmektedir (Şekil 9).

Genel olarak 3,4,5 no'lu profillerde yüksek hızlı sokulumlar ( $\mathrm{Vp}>6,2 \mathrm{~km} / \mathrm{sn}$ ), mikro-çatlaklar boyunca yüzeye taşınmış alt kabuk yapısı ile ilişkilidir.

\subsection{Düşük Vp, Yüksek Vp/Vs (Low Vp, High Vp/Vs)}

Bu tür anomaliye neden olan birkaç faktör söz konusudur. Bunlardan en önemlilerinden biri suya doygun sedimanter havzaların genelde düşük $\mathrm{Vp}$, yüksek $\mathrm{Vp} / \mathrm{Vs}$ oranı göstermesidir. Suya doygun kırıklı, çatlaklı ve gözenekli yapılar, yüksek akışkan içeriği nedeniyle düşük S-dalga hızı göstermesinden dolayı yüksek $\mathrm{Vp} / \mathrm{Vs}$ modeli sunarlar. Bir diğer önemli faktör de fay zonlarının varlığıdır. Eğer bölgenin tektonik rejimi farklı fay sistemleri tarafından denetleniyorsa, fay zonlarının olduğu bölgelerde de bu tür modeller gözlenmektedir.
Nitekim çalışma alanında bu tür model davranışı en çok GF, KFZ, MFZ ve ZBFZ'na ait sı ğ derinliklerde gözlenmiştir (Şekil 9; 2-4-6. profiller). GF zonundaki düşük P-dalga hızı ve yüksek $\mathrm{Vp} / \mathrm{Vs}$ oranı, $10 \mathrm{~km}$ derinliğe kadar devam etmektedir (Şekil 9, 3. profil). 2.profilde AJS, 6.profilde Nif Dağ $_{1} \quad(\sim 70 \mathrm{~km})$ altında yer alan $\mathrm{Vp} / \mathrm{Vs}$ oranları incelendiğinde düşük $\mathrm{Vp} / \mathrm{Vs}$ ile çevrelenmiş $\sim 10-15 \mathrm{~km}$ yüksekliğinde, $\sim 5 \mathrm{~km}$ genişliğinde yüksek $\mathrm{Vp} / \mathrm{Vs}$ oranına sahip yerel sokulumlar tespit edilmiştir. Litolojik olarak bu yapılar kuzeyde Miyosen volkanikler (AJS) ve güneyde geç Kretase-Paleosen yaşlı kireçtaşı, volkanik, serpantin içeren Bornova Filiş Zonu (Nif Dağı) ile ilişkilidir [7].

\subsection{Yüksek Vp, Yüksek Vp/Vs (High Vp, High Vp/Vs)}

Genel olarak bu tür anomaliler, akışkan içeriği yüksek olan bölgelerde ve fay zonları çevresinde gözlenmektedir. Kayaçların pekleşmiş olmasıyla da ilişkilidir. Çalışma alanında bu tür hız modelleri SFZ boyunca ve körfez içinde gözlenmektedir. Şekil 9'da 1 no'lu profilde, AJS ile ZBFZ arasında kalan kesimde, alt kabuktan başlayıp sığ kesimlerde $10 \mathrm{~km}$ derinliğe doğru sokulum yapan yüksek hızlar ( $\mathrm{Vp}>6,5$ $\mathrm{km} / \mathrm{sn}$ ) ve yükssek $\mathrm{Vp} / \mathrm{Vs}$ oranları $(>1,8)$, orta miyosen yaşlı dasit ve riyolitten oluşan volkanik birimlerin, kırık ve çatlaklar yoluyla derinden yüzeye doğru taşınmasıyla açıklanabilir [50]. 4 no'lu profilde, SFZ ve SJS ile ilişkili olan sismojenik zonun kalınlığı, diğer bölgelerle karşılaştırıldığında daha incedir $(\sim 6 \mathrm{~km})$. 4-5-6 no'lu profillerin sonlarında görülen yüksek $\mathrm{Vp}$ ve yüksek $\mathrm{Vp} / \mathrm{Vs}$ değerleri, daha genç döneme ait birimler (holosen, miyosen) içinde konumlanmış Mezozoik yaşlı pekleşmiş kireçtaşları ile ilişkilidir [50]. 


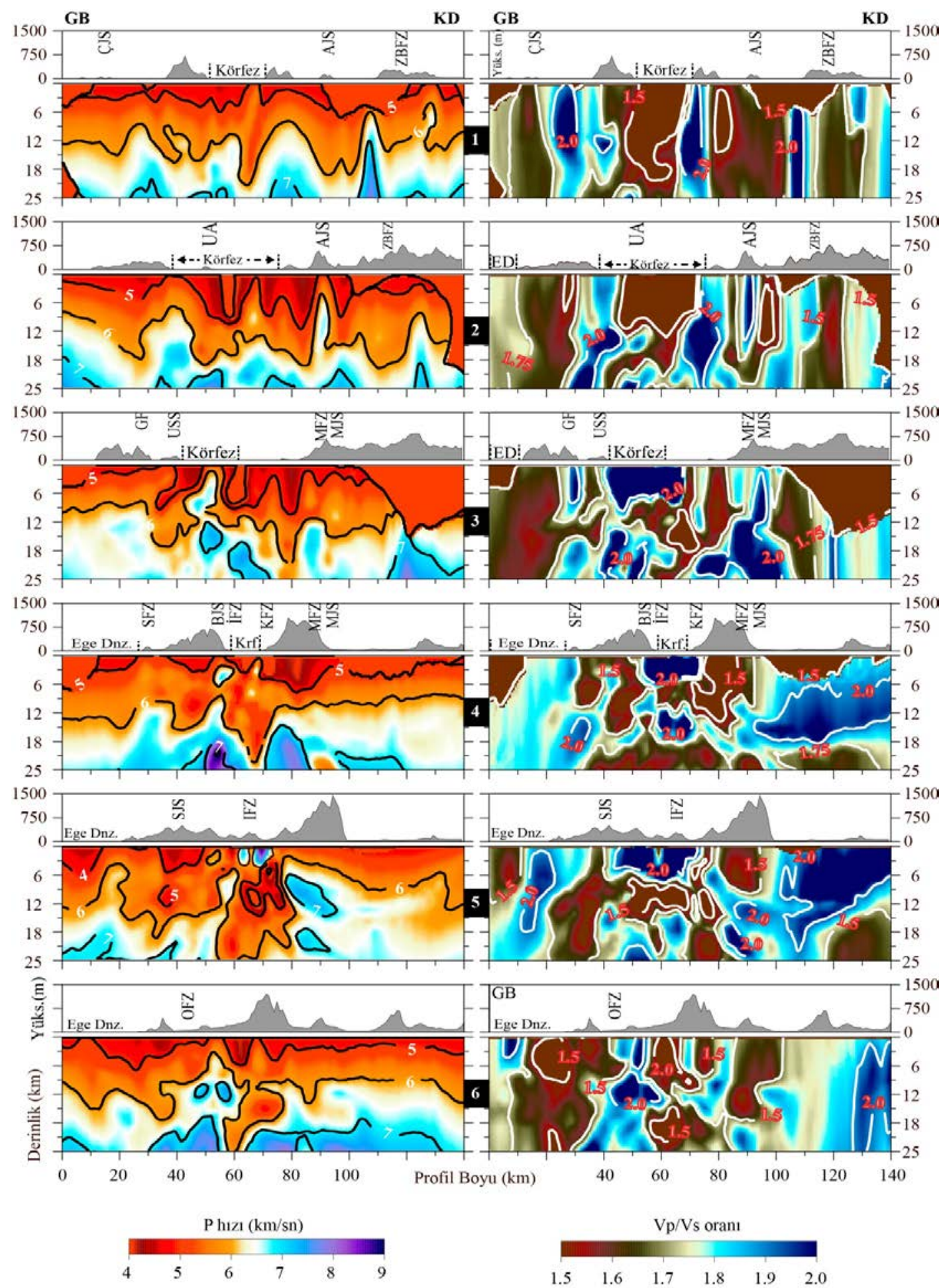

Şekil 9. İzmir ve çevresi için P-dalgası gerçek düşey kesit ve Vp/Vs düşey kesit sonuçları (Vertical depth-cross section results for P-absolute velocity and Vp/Vs ratio of Izmir and surrounding area)

\section{SONUÇLAR VE TARTIŞMALAR (RESULTS AND DISCUSSIONS)}

İzmir ve çevresinde meydana gelen 1723 depremden en iyi çözüm kalitesine sahip 773 deprem verisi, 3-B yerel deprem tomografisi yöntemiyle çalışma alanının sismik hız yapısının ortaya konması amacıyla kullanılmıştır. Bu doğrultuda 44 744 istasyon tarafindan kaydedilen 7556 P- ve 6381 S-fazı kayıtları analiz edilmiştir. Çalışma sonucunda İzmir ve yakın çevresinin $25 \mathrm{~km}$ derinliğe kadar 3-B sismik hız yapısı ortaya konmuştur. P hızı ve Vp/Vs modelleri litolojik bulgularla birlikte yorumlanmıştır. Çalışma alanında farklı P- dalga hızı ve $\mathrm{Vp} / \mathrm{Vs}$ oranına sahip 4 ayrı sismik hız zonu belirlenmiştir. Bunlardan en üstte yer alan $\sim 7 \mathrm{~km}$ kalınlıktaki üst katmana 
ait hızların $\mathrm{Vp}<5 \mathrm{~km} / \mathrm{sn}$ 'den düşük olduğu gözlenmiş ve bu yapı genç çökellerle ilişkilendirilmiştir. Bir alt katmana ait hız zonunun depremlerin yoğun meydana geldiği sismojenik zon olduğu gözlenmiş, bu katman kalınlığının da $\sim 8 \mathrm{~km}$ civarında olduğu belirlenmiştir. $7-15 \mathrm{~km}$ derinlikler arasında ortalama $6,3 \mathrm{~km} / \mathrm{sn}$ P-dalga hızına sahip olan bu orta katmana ait litoloji genel olarak magmatik kökenlidir. Alt kabuk olarak nitelendirilen, gabro ve okyanusal kayaçlarla ilișkilendirilen bir sonraki katman kalınlığının $\sim 9 \mathrm{~km}$ olduğu, 15-24 km derinlikler arasında yer aldığı ve 6,2-7,4 $\mathrm{km} / \mathrm{sn}$ arasında değişen P-dalga hızlarına sahip olduğu tespit edilmiştir. P- hızının 7,4 km/sn'den daha fazla olduğu bir alt katman kabuk kabuk-manto sınırına işarete etmektedir. Çalışma alanına ait kabuk-manto sınırının ortalama $24 \mathrm{~km}$ derinde ve dalgalı bir yüzeye sahip olduğu gözlenmiştir.

Çalışma alanında 3 farklı hız modeli gözlenmiştir. Bunlar; 1) Düşük $V p$ ve düşük $V p / V s, 2)$ Düşük $V p$ ve yüksek $V p / V s$, 3) Yüksek Vp ve yüksek Vp/Vs şeklindedir. BJS, ÇJS, MJS ve SJS gibi yüksek gaz içeriği ihtiva eden jeotermal alanlarda, OFZ ve ZBFZ gibi karmaşık tektonizmaya sahip olan farklı derinliklerde genelde düşük $\mathrm{Vp}$ ve düşük $\mathrm{Vp} / \mathrm{Vs}$ modelleri elde edilmiştir. GF, KFZ, MFZ, İFZ ve gibi önemli fay zonları ile birlikte AJS, Foça ve Nif Dağı civarlarının ise çoğunlukla düşük $\mathrm{Vp}$ ve yüksek $\mathrm{Vp} / \mathrm{Vs}$ oranlarıyla temsil edildiği gözlenmiştir. Vp hızına göre Vs hızının çok daha fazla oranda düşmesinden dolayı bu tip anomalilerin sıvı içeriğinden kaynaklandığı sonucuna ulaşılmıştır. Öte yandan yüksek Vp ve yüksek Vp/Vs modellerinin, İzmir iç körfezin bazı kesimlerinde ve SFZ'na ait yüzey kesimlerden derinlere doğru mevcut olduğu belirlenmiştir. $\mathrm{Bu}$ model jeotermal sistemlerin varlığıyla ilişkilendirilmiştir. İzmir Körfezi ve İFZ altındaki karmaşık Vp/Vs oranları, zayıflık zonundaki gaz içeriğinden kaynaklanmaktadır. KD-GB doğrultulu derinlik kesitinde (Şekil 9, 4 no’lu profil) $\sim 50 \mathrm{~km}$ uzunluğunda ve $\sim 4 \mathrm{~km}$ kalınlığında tespit edilen düşük $\mathrm{Vp} / \mathrm{Vs}$ ve düşük Vp modelinden, SFZ-MFZ arasında kalan geniş bir bölgede henüz keşfedilmemiş $\mathrm{CO}_{2} \mathrm{vb}$. gibi gazlar ihtiva edebilecek potansiyel alanlar olabileceği sonucuna ulaşılmıştır.

\section{TEŞEKKÜR (ACKNOWLEDGEMENT)}

Bu çalışma, Dokuz Eylül Üniversitesi, Fen Bilimleri Enstitüsü Jeofizik Mühendisliği Anabilim Dalında doktora eğitimi gören Arş. Gör. Çağlar Özer' in tez çalışmalarının bir bölümünü oluşturmaktadır. Tomografik hesaplamalar Ivan Koulakov'a ait LOTOS v12 [6] algoritması kullanılarak yapılmıştır. Şekillerin büyük bir kısmı GMT [62] programı kullanılarak hazırlanmıştır. Deprem faz okumaları SEISAN [63] programı yardımıyla yapılmıştır. $\mathrm{Bu}$ araştırmaya veri desteği sağlayan T.C. Başbakanlık Afet ve Acil Durum (AFAD) Yönetimi Deprem Dairesi Başkanlığına, Uluslararası Sismoloji Merkezi (ISC)'ne, Atina Ulusal Gözlemevine (NOA), Boğaziçi Üniversitesi Kandilli Rasathanesi ve Deprem Araştırma Enstitüsüne (KRDAE) ve bilgisayar altyapısından yararlandığımız Dokuz Eylül Üniversitesi Sismoloji Laboratuarına (DEÜ SismoLab) teşekkür ederiz. Bu araştırma, DEÜ-BAP (2016.KB.
FEN.013) bilimsel araştırma projesi kapsamında desteklenmiştir.

\section{KAYNAKLAR (REFERENCES)}

1. Barış Ş., Nakajima J., Hasegawa A., Honkura Y., Ito A., Uçer B., Three-dimensional structure of $\mathrm{Vp}, \mathrm{Vs}$ and $\mathrm{Vp} / \mathrm{Vs}$ in the upper crust of the Marmara region, NW Turkey, Earth Planets Space, 75 (11), 1019-1038, 2005.

2. Zhao D., Hasegawa A., Horiuchi S., Tomographic imaging of $\mathrm{P}$ and $\mathrm{S}$ wave velocity structure beneath northeastern Japan, J. Geophys. Res., 97 (B13), 1990919928, 1992.

3. Kaypak B., Three-dimensional Vp and Vp/Vs structure of the upper crust in the Erzincan basin (eastern Turkey), J. Geophys. Res., 113 (B7), 2008.

4. Thurber C. H., Earthquake locations and threedimensional crustal structure in the Coyote Lake area, central California, J. Geophys. Res., 88 (B10), 82268236, 1983.

5. Koulakov I., Bindi D., Parolai S., Grosser H., Milkereit C., Distribution of seismic velocities and attenuation in the crust beneath the North Anatolian Fault (Turkey) from local earthquake tomography, Bull. Seism. Soc. Am., 100 (1), 207-224, 2010.

6. Koulakov I., LOTOS code for local earthquake tomographic inversion: Benchmarks for testing tomographic algorithms, Bull. Seism. Soc. Am., 99 (1), 194-214, 2009.

7. Kaypak B., Gökkaya G., 3-D imaging of the upper crust beneath the Denizli geothermal region by local earthquake tomography Western Turkey, J. Volc. Geotherm. Res., 211-212 (1), 47-60, 2012.

8. Cambaz M.D., Karabulut H., Love Wave Group Velocity Maps of Turkey and Surrounding regions, Geophys. J. Int., 181 (1), 502-520, 2010.

9. Tezel T., Shibutani T., Kaypak B., Crustal structure variation in western Turkey inferred from the receiver function analysis, Tectonophysics, 492 (1-4), 240-252, 2010.

10. Mutlu A.K., Karabulut H., Anisotropic Pn tomography of Turkey and adjacent regions, Geophys. J. Int., 187 (3), 1743-1758, 2011.

11. Salaun G., Pedersen H.A., Paul A., Farra V., Karabulut H., Hatzfeld D., Papazachos C., Childs D.M., Pequegnat C., SIMBAAD Team, High-resolution surface wave tomography beneath the Aegean-Anatolia region: constraints on upper-mantle structure, Geophys. J. Int., 190 (1), 406-420, 2012.

12. Karabulut H., Paul A., Ergün A.T., Hatzfeld D., Childs D.M., Aktar M., Long-wavelength undulations of the seismic Moho beneath the strongly stretched Western Anatolia, Geophys. J. Int., 194 (1), 450-464, 2013.

13. Özmen B., Can H., Deterministic seismic hazard assessment for Ankara, Turkey, Journal of the Faculty of Engineering and Architecture of Gazi University, 31 (1), 9-18, 2016.

14. Seyrek E., Tosun H., Influence of analysis methods for seismic hazard on total risk of large concrete dams in 
Turkey, Journal of the Faculty of Engineering and Architecture of Gazi University, 28 (1), 67-75, 2013.

15. Sönmezler Y.B., Akbaş S.O., Işık N.S., Assessment of the peak acceleration, amplification ratio and fundamental period properties for the Kirikkale province settlement area, Journal of the Faculty of Engineering and Architecture of Gazi University, 30 (4), 711-721, 2015.

16. Barka A.A., The North Anatolian Fault Zone, Annales Tectonicae, 6 (1), 164-195, 1992.

17. Dewey J.F., Şengör A.M.C., Aegean and surrounding regions: complex multiple and continuum tectonics in a convergent zone, Geol. Soc. Am. Bull., 90 (1), 84-92, 1979.

18. Tezel T., Erduran M., Alptekin Ö., Crustal shear wave velocity structure of Turkey by surface wave dispersion analysis, Annals of Geophysics, 50 (2), 177-190, 2007.

19. Le Pichon X., Angelier J., The Hellenic Arc and trench system: A key to the Neotectonic evolution of the Eastern Mediterranean area, Tectonophysics, 60 (1), 142, 1979.

20. Le Pichon X., Angelier J., The Aegean Sea, Philosophical Transactions of the Royal Society of London, A300, 357-372, 1981.

21. Emre Ö., Özalp S., Doğan A., Özaksoy V., Yıldırım C., Göktaş F., İzmir yakın çevresinin diri fayları ve deprem potansiyelleri, MTA Rapor No:10754, Jeoloji Etütleri Dairesi Başkanlığı, 2005.

22. Emre Ö., Duman T.Y., Özalp S., Elmacı H., Olgun Ş., Şaroğlu F., 1/1.125.000 Ölçekli Türkiye Diri Fay Haritası, Maden Tetkik ve Arama Genel Müdürlüğü Özel Yayınlar Serisi, Ankara, Türkiye, 2013.

23. Magri F., Akar T., Gemici U., Pekdeger A., Numerical investigations of fault-induced seawater circulation in the Seferihisar-Balçova geothermal system, western Turkey, Hydrol. J., 20 (1), 103-118, 2012.

24. Özkan R., Şener M., Helvacı C., Şener M.F., Aliağa (İzmir) jeotermal alanındaki hidrotermal alterasyon ve termal sularla ilişkili, Yerbilimleri, 32 (1), 1-20, 2011.

25. Pamukcu O., Gonenc T., Sindırg1 P., Baba A., Application of geophysical methods in Gulbahce geothermal site, Urla-Izmir, western Anatolia, Geothermal Systems and Energy Resources, Editör: Baba, A., Bundschuh, J., Chandrasekharam, D., Sustainable energy developments, CRC Press, Netherlands, 251-257, 2014.

26. Erkan K., Geothermal investigations in western Anatolia using equilibrium temperatures from shallow boreholes, Solid Earth, 6 (1), 103-113, 2015.

27. Erdoğan B., İzmir-Ankara Zonu İle Karaburun Kuşağının Tektonik İlişkisi, MTA Dergisi, 110 (1), 115, 1990.

28. Erdoğan B., Altıner D., Güngör T., Özer S., Karaburun yarımadasının stratigrafisi, MTA Dergisi, 111 (1), 1-23, 1990.

29. Uzel B., Sozbilir B., Ozkaymak C., Neotectonic evolution of an actively growing superimposed basin in western Anatolia: The Inner Bay of Izmir, Turkey, Turkish J. Earth Sci., 21 (1), 439-471, 2012.
30. Coskun S., Dondurur D., Cifci G., Aydemir A., Drahor M.G., Natural and anthropogenic submarine morphologies revealed by high resolution acoustic data in the Gulf of Izmir, western Turkey, Mar. Pet. Geol., 71 (1), 211-224, 2015.

31. Ersoy E.Y., Cemen I., Helvaci C., Billor Z.,. Tectonostratigraphy of the Neogene basins in western Turkey: Implications for tectonic evolution of the Aegean Extended Region, Tectonophysics, 635 (1), 33-58, 2014.

32. T.C. Başbakanlık Afet ve Acil Durum Yönetimi Başkanlığı Deprem Dairesi Başkanlığı, http://www.deprem.gov.tr, Ankara, Türkiye, 2015.

33. Polat O., Ceken U., Uran T., Gok E., Yilmaz N., Beyhan M., Koc N., Arslan B., Yilmaz D., Utku M., IzmirNet: A strong-motion network in metropolitan Izmir, Western Anatolia, Turkey, Seism. Res. Lett., 80 (5), 831-838, 2009.

34. Permanent Regional Seismological Network operated by the Aristotle University of Thessaloniki,http://geophysics.geo.auth.gr,doi:10.7914/ SN/HT.,http://geophysics.geo.auth.gr/, Atina, Yunanistan, 2015.

35. International Seismological Centre, On-line Bulletin, http://www.isc.ac.uk, Internatl. Seis. Cent., Thatcham, United Kingdom, 2013.

36. Boğaziçi Üniversitesi Kandilli Rasathanesi ve Deprem Araştırma Enstitüsü Bölgesel Deprem-Tsunami İzleme ve Değerlendirme Merkezi, http://www.koeri.boun.edu.tr, İstanbul, Türkiye, 2015.

37. Lee W.H.K., Lahr J.C., HYPO71 (Revised): A computer program for determining hypocenter, magnitude, and first motion pattern of local earthquakes, Open File Report, 75-311, 64 p, 1975.

38. Tunç B., Marmara bölgesinin üç boyutlu hız yapısının sismik tomografi yöntemi ile belirlenmesi, Doktora Tezi, Kocaeli üniversitesi, Fen Bilimleri Enstitüsü, 2008.

39. Özer Ç., Polat O., İzmir ve çevresinin 1-B (Bir-Boyutlu) sismik hız yapısının belirlenmesi, DEÜ-Mühendislik Fakültesi Fen ve Mühendislik Dergisi, 19 (55), 147-168, 2017.

40. Jaxybulatov K., Koulakov I., Ibs-von Seht M., Klinge K., Reichert C., Dahren B., Troll V.R., Evidence for high fluid/melt content beneath Krakatau volcano (Indonesia) from local earthquake tomography, J. Volc. Geotherm. Res., 206 (3-4), 96-105, 2011.

41. Khrepy S., Koulakov I., Arifi N., Crustal structure in the area of the cannon earthquakes of Abu Dabbab (Northern Red Sea, Egypt), from Seismic Tomography Inversion, Bull. Seism. Soc. Am., 105 (4), 2015.

42. Murphy A.R., Thurber C., Prejean S., Bennington N., Three-dimensional seismic velocity structure and earthquake relocations at Katmai, J. Volc. Geotherm. Res., 276 (1), 121-131, 2014.

43. Salah M.K., Sahin S., Topatan U., Crustal velocity and $\mathrm{Vp} / \mathrm{Vs}$ structures beneath central Anatolia from local seismic tomography, Arabian J. Geosci., 7 (10), 41014118, 2014. 
44. Seghedi I., Helvacı C., Pécskay Z., Composite volcanoes in the south-eastern part of İzmir-Balıkesir transfer Zone,Western Anatolia, Turkey, J. Volc. Geotherm. Res., 291 (1), 72-85, 2015.

45. Ozkan R., Sener M., Helvaci C., Sener M.F., Hydrothermal alterations and relationship with thermal waters at Aliaga (Izmir) geothermal field, Bull. Earth Sci., 32 (1), 1-20, 2011.

46. Yilmazer S., Alacali M., Distribution of hot water resources and potentials of Izmir province, Proceedings World Geothermal Congress, Antalya, Turkey, 1-5, 2429 Nisan 2005.

47. Serpen U., Aksoy N., Ongur T., Korkmaz E.D., Geothermal energy in Turkey: 2008 update, Geothermics, 38 (2), 227-237, 2009.

48. Hauksson E., Crustal structure and seismicity distribution adjacent to the Pacific and North America plate boundary in southern California, J. Geophys. Res., 105 (B6), 2000.

49. Uzel B., Sozbilir H., Ozkaymak C., Kaymakci N., Langereis C.G., Structural evidence for strike-slip deformation in the Izmir-Balikesir transfer zone and consequences for late Cenozoic evolution of western Anatolia (Turkey), J. Geodyn., 65 (1), 2013.

50. Akbaş B., Akdeniz N., Aksay A., Altun İ., Balcı V., Bilginer E., Bilgiç T., Duru M., Ercan T., Gedik İ., Günay Y., Güven İ.H., Hakyemez H.Y., Konak N., Papak İ., Pehlivan Ş., Sevin M., Şenel M., Tarhan N., Turhan N., Türkecan A., Ulu Ü., Uğuz M.F., Yurtsever A. ve diğerleri, Türkiye Jeoloji Haritası, Maden Tetkik ve Arama Genel Müdürlüğü Yayını, Ankara, Türkiye, 2011.

51. Ulugergerli E.U., Seyitoğlu G., Başokur AT., Kaya C., Dikmen U. Candansayar ME., The geoelectrical structure of northwestern Anatolia, Turkey, Pure Appl. Geophys., 164, 999-1026, 2007.

52. Pamukcu O., Yurdakul A., Isostatic compensation in western Anatolia with estimate of the effective elastic thickness, Turkish J. Earth Sci., 17, 545-557, 2008.

53. Çiftçi G., Pamukçu O., Çoruh C., Çopur S., Sözbilir H., Shallow and deep structure of a supradetachment basin based on geological, conventional deep seismic reflection sections and gravity data in the Buyuk Menderes Graben, western Anatolia, Surv. Geophys., 32, 271-290, 2011.

54. Komut T., Gray R., Pysklywec R., Göğüş O.H., Mantle flow uplift of western Anatolia and the Aegean: Interpretations from geophysical analyses and geodynamic modeling, J. Geophys. Res., 117 (B11412), 1-14, 2012.

55. Vanacore E.A., Taymaz T., Saygin E., Moho structure of the Anatolian Plate from receiver function analysis, Geophys. J. Int., 193 (1), 329-337, 2013.

56. Delph J.R., Biryol C.B., Beck S.L., Zandt G., Shear wave velocity structure of the Anatolian Plate: anomalously slow crust in southwestern Turkey, Geophys. J. Int., 2002 (1), 261-276, 2015.

57. Kind R., Eken T., Tilmann F., Sodoudi F., Taymaz T., Bulut F., Yuan X., Can B., Schneid F., Thickness of the lithosphere beneath Turkey and surroundings from Sreceiver functions, Solid Earth, 6 (1), 971-984, 2015.

58. Muksin U., Bauer K., Haberland C., Seismic Vp and $\mathrm{Vp} / \mathrm{Vs}$ structure of the geothermal area around Tarutung (North Sumatra, Indonesia) derived from local earthquake tomography, J. Volc. Geotherm. Res., 260 (1), 27-42, 2013.

59. Totaro C., Koulakov I., Orecchioa B., Prestia D., Detailed crustal structure in the area of the southern Apennines-Calabrian Arc border from local earthquake tomography, J.Geodyn., 82 (1), 87-97, 2014.

60. Yolsal-Cevikbilen S., Biryol C.B., Beck S., Zandt G., Taymaz T., Adiyaman H.E., Ozacar A.A., 3-D crustal structure along the North Anatolian Fault Zone in northcentral Anatolia revealed by local earthquake tomography, Geophys. J. Int., 188 (3), 819-849, 2012.

61. Ozer C., Polat O., Local earthquake tomography of Izmir geothermal area, Aegean region of Turkey, B. Geofis. Teor. Appl., 58 (1), 17-42, 2017.

62. Wessel P., Smith W.H.F., GMT Version 5.1-Generic mapping tools graphics, Laboratory for Sattelite Altimetry, NOAA/NESDIS/NODC, 123 p. 2004

63. Havskov J., Ottemoller L., SeisAn earthquake analysis software, Seism. Res. Lett., 70 (1), 532-534, 1999. 
